\title{
Performance of Shari'ah based Investment: Evidence from Pakistani Listed Firms
}

\author{
Hilal Anwar Butt ${ }^{1}$, Mohsin Sadaqat ${ }^{2}$
}

\begin{abstract}
The investment universe of Shariah Compliant (SC) equities is relatively smaller compared to the investment universe of Non-Shari'ah Complaint (NSC) equities due to the imposition of Shari'ah specific filters. Therefore, under the diversification theory, it is argued that portfolios constructed by using SC equities are suboptimal. To empirically test this notion, the main purpose of this study is to investigate that either the SC portfolios (faith bound investors) forego some part of returns or hedged against market risks while fulfilling their religious obligations. To test the foregoing, we imply simple asset pricing techniques which are in vogue in conventional finance. Firstly, we segregate the firms listed at Pakistan Stock Exchange (PSX) into SC and NSC stocks. Then, we form two portfolios within each group based on market capitalization and volatility. The purpose is to analyze and compare the performance of these two groups while controlling for firms related characteristics such as size and volatility. The data coverage is from January 2004 until June 2016. Our results indicate that in most of the cases the risk-adjusted returns (alphas) for the returns differential between SC and NCS firms are positive. This is mainly because the SC firms in comparison to their counterparts in PSX, provides excess returns that are hedged against market, size and value based systematic risks factors. Overall, these results reconcile with one prevailing notion that the SC stocks that have lower financial leverage and higher investment in real assets are lesser exposed to market risks. Further, the SC firms that are more capitalized and lesser volatile, perform better than lower capitalized and higher volatile SC and NSC firms. To sum up our results, we do not find any substantial evidence for opportunity loss due to limited diversification opportunities in case of SC firms. This paper highlights that Islamic funds have potential to fulfil the demands of risk averse investors who are also faith bound.
\end{abstract}

Keywords: Diversification; performance; risk adjusted returns; Shari'ah compliant stocks.

JEL Classification: G11 G15 G23

1 Associate Professor and Research Fellow, Institute of Business Administration, Karachi, Pakistan.

Email: habutt@iba.edu.pk

2 Assistant Professor, National University of Sciences and Technology (NUST), Islamabad, Pakistan.

Email: mohsin.sadaqat@nbs.nust.edu.pk

\begin{tabular}{ll} 
ARTICLE HISTORY & \\
19 Oct, 2018 Submission Received & 11 Nov, 2018 First Review \\
\hline 28 May, 2019 Second Review & 20 Aug, 2019 Third Review \\
\hline 14 Sep, 2019 Accepd
\end{tabular}

14 Sep, 2019 Accepted 


\section{Introduction}

In the recent past, certain types of funds/portfolios such as Socially Responsible (SR) funds and Shari'ah Compliant (SC) funds have shown tremendous growth globally (Chowdhury \& Masih, 2015). The distinguishing feature of these two categories of investments relative to other investments (non-constrained) is that they impose certain restrictions on equities/stocks and hence such stocks/equities are excluded from the opportunity set. Since both of these categories of investments are restrictive in nature, often SC investments are considered under the umbrella of SR investments (Chowdhury \& Masih, 2015).

In Pakistan, Over the last 15 years, SC mutual fund industry that comprises mainly of equities have shown a swift growth of about $45 \%$ annually relative to the $20 \%$ annual growth of conventional mutual fund industry ${ }^{3}$. Resultantly, the SC funds grew from 2\% (1 billion PKR) in 2003 to 38\% (241 billion PKR) in 2018. In addition to this, over the past six years, the KMI-30 Index, an Index that comprises of the SC equities launched by Pakistan Stock Exchange (PSX) in collaboration with Al Meezan, has outperformed (25\% annual growth) the KSE-100 index (24\% annual growth) by $1 \%$ annually. This better performance of SC funds over the Non-SC funds attracted investors to invest in $\mathrm{SC}$ avenues. However, to understand the performance of SC and NSC firms, their risk-return trade-off is required to be studied in more detail. This is an important issue because apart from the tremendous growth in SC funds globally and specifically in Pakistan, the past literature documented two opposing views. The first view is that the SR/SC portfolios restricts investments in certain types of stocks therefore, this act violates the fundamental theory of diversification (Bello, 2005). This asserts that the portfolio constructed based on SR/SC stocks is under diversified and hence sub optimal. While the other view supports the SR/SC investments. They believe that such constrained investments are optimal and well diversified. Since, the screening process help to select only stocks that are financially strong, profitable, low leveraged and more stable (Chowdhury \& Masih, 2015). Therefore, the extra filters minimize the risk and leads to good investments (Abdullah, Hassan, \& Mohamad, 2007).

To assess the risk-return trade-off, in empirical asset pricing literature, portfolios are constructed by aggregating the stocks based on their available characteristics at time $t$ such as size, value, dividend yield, operating profitability, momentum and others. Then the return dispersion at time $t^{+} n^{4}$ between portfolios (commonly known

3 These statistics are provided in a report provided by Islamic Finance News, 2018. The title of the report is "Current outlook for Islamic asset management and the fund industry in Pakistan". https:// www.islamicfinancenews.com/current-outlook-for-islamic-asset-management-and-the-fund-industry-in-pakistan.html 4 Where $n$ denotes the time period ahead current time t. 
as zero-investment strategy) having extreme characteristics ${ }^{5}$ is recorded overtime for a given trading frequency. Lastly, these returns are modeled using Capital Asset Pricing Model (CAPM) of Sharpe (1964) and Lintner (1965), 3 and 5 factor models of Fama and French (1993, 2015), and q-model of (Hou, Xue \& Zhang, 2015). The main premise is to gauge the magnitude and statistical significance of risk-adjusted returns (alphas) of these trading strategies. Whereas, the positive alpha indicates the superior performance and negative the inferior.

This paper adopts the same asset pricing paradigm to ponder upon the performance of stocks which are screened through Shari'ah based guidelines. These guidelines mainly select the stocks based on financial leverage, investments in real assets and income from interest bearing instruments. One may argue the merits of the selection criteria, such as these result into lesser diversified investment strategy because it forbids to select those stocks which are otherwise less correlated with the stocks that are allowed for investment (Shari'ah screen stocks). This negates the Markowitz (1952) portfolio selection logic, in which constituent stocks correlation structure predominates the portfolio variance/risk. In the study of Ashraf, Felixson, Khawaja and Hussian (2017), it is shown that the efficient frontier of unconstrained conventional portfolios offers better choices, in terms of risk and returns to the investors. In comparison to the efficient frontier extended by the constrained portfolios composed of Shari'ah screened stocks.

Despite this theoretical disadvantage of squeezed frontier, the Shari'ah guidelines suggesting the lesser leveraged firms with higher investment in real assets have an advantage. Such that, these guidelines naturally select those firms which provide higher returns when market returns are lower. Therefore, for fulling this motive of investors to provide higher consumption when marginal utility of consumption is higher, investors are willing to receive overall lower returns. For instance, Hou, Xue and Zhang (2015) enunciates that the high leverage indicates lower growth opportunities and investments and therefore higher expected returns. Whereas, lower leverage suggests more growth opportunities, higher investments and therefore lower expected returns. To, this end there are studies Aka (2009); Alhenawi, Hassan and Merdad (2010); Sukmana and Kolid (2012); Ho, Rahman, Yusuf and Zamzamin (2014) which suggest the performance of Shari'ah screened stocks is better in recession.

5 For example, the return dispersion between the high/low capitalized firms (size premium, documented by Banz (1981) and others), the different types of value premium between firms having lower/higher price to their earnings and dividends (Basu (1977), Jaffe, Keim, and Westerfield (1989). Similarly, the value premium is also documented between the firms with higher/lower book-to-market of equity (Rosenberg, Reid, and Lanstein (1985), Fama and French (1992, 1993) and others). There is a long list of such stock's related characteristics which produces the return spread, in recent working paper Hou, Xue and Zhang (2017) documented 447 of them, although the most of them are not significant at higher statistical significance threshold. 
In the end the compulsion of investing in Shari'ah screen stocks either results in lesser diversified/risky portfolios or fulfils investors hedging needs is an empirical question. The natural choice is to test if the SC stocks provide higher or lower risk-adjusted returns (alphas) in comparison to their counterfactual NSC stocks? This kind of study can be undertaken on the line of Fama and French (2010), in which performance of active funds versus passive funds is analyzed. Therefore, we use Fama and French (1993) model to extract risk adjusted return differential between SC and NSC for the stocks traded in PSX for the time period of May 2004 to February 2016 (2004-2016). These results have importance for those investors, who either look for an investment in SC stocks by virtue of their faith or who demand higher risk-adjusted returns (alphas).

To control for the volatility and size of both SC and NSC stocks we construct two portfolios using the median of volatility and size for these two groups of stocks. The average returns, standard deviations and thus the Sharpe ratios of both the Higher Volatile Shari' ah Compliant Stocks (HVSC) and Lower Volatility Shari'ah Compliant (LVSC) Stocks are higher in comparison to their counterpart Higher Volatility NonShari'ah Compliant Stocks (HVNSC) and Lower Volatile Non-Shari'ah Compliant Stocks (LVNSC). Further to understand their market related risk compensation the four series of return differential are regressed on the market, size and value related factors of Fama and French (1993) model.

We find that the alphas for the time series of two return differentials of LVSC-HVNSC (that is long in low volatility SC and short in high volatility NSC stocks) and HVSC-HVNSC (that is long in high volatility SC and short in high volatility NSC stocks) are economically large and statistically the most significant. For former the monthly alpha is $1.58 \%$ and for later it is $1.44 \%$. It is interesting to note that average raw returns differentials on these strategies are $-0.29 \%$ and $0.51 \%$. Even for the strategy LVSC-LVNSC (that is long in low volatility SC and short in low volatility NSC stocks) the monthly alphas are higher than their monthly average return differential. These results indicate that SC stocks are hedged against market-based risks and provide higher risk-adjusted returns to its investors and it is especially visible for LVSC stocks 6 .

Whereas, the Small Shari'ah Compliant (SSC) stocks have lower Sharpe ratio in comparison to Small Non-Shari'ah Compliant Stocks (SNSC), however the Big Shari'ah Compliant Stocks (BSC) have higher Sharpe ratio in comparison to both Big Non-Shari'ah Compliant stocks (BNSC) and SNSC stocks. As regards the 3-factor alphas, they are always economically big and significant for the zero cost strategies such

6 The only strategy HVSC-LVNSC has monthly alphas which is although positive but still lower than its average monthly return. 
as BSC-SNSC (long in BSC and short in SNSC stocks) and BSC-BNSC (long in BSC and short in BNSC stocks), and these alphas are higher than their time series average. Here as well it is noticed that risk hedging properties of SC stocks remained intact when they are portioned into portfolio in accordance with their market capitalization. In nutshell, the SC stocks which are lesser volatile and of bigger size provides better risk-adjusted returns to their investors.

The rest of the paper is organized as such that in Section 2 we have discussed the previous literature, Section 3 discusses the research methodology, the results are discussed and analyzed in Section 4 and finally Section 5 concludes the discussion.

\section{Literature Review}

The literatures on constrained portfolios/funds is available in two main streams (Chowdhury \& Masih, 2015). The first stream of literature concentrated on SR investments which allow investing based upon ethical and moral grounds. While the other stream of literatures focuses on SC investments which is based on the Islamic Law. Since the focus of this study is on SC stream, therefore the literatures mainly focus on this stream.

Prior studies compare the performance of Shari'ah and Conventional indices, funds and portfolios in risk-return framework (Mansur, Nazrol \& Obiyathulla, 2018). Few studies provide evidence that conventional stocks outperform SC stocks (Hayat \& Kraeussl, 2011; Al-Khazali, Lean \& Samet, 2014). The argument for poor performance of Islamic stocks is that Shari'ah rulings restrict investments in interest bearing stocks. Therefore, the investment universe of Islamic stocks is relatively small compared to conventional stocks. It implies that Islamic stocks are unable to reduce the idiosyncratic risk (Al-Shakfa \& Lypny, 2011). However, there are studies which show that Islamic stocks performed relatively better than secular stocks (Alam \& Rajjaque, 2010; Bousalam \& Hamzaoui, 2016; Ashraf \& Mohammad, 2014). The lower systematic risk is the main reason for better performance of Islamic stocks (Ashraf \& Mohammad, 2014). Peillex and Ureche-Rangau (2013) studied the relative performance of Shari'ah and Non-Shari'ah indices in long and short run using the French data set. They found that Islamic indices outperform the conventional counterparts. Moreover, Charles, Darne, and Pop (2015) provided evidence that conventional indices either under-performed Islamic indices or their performance is statistically indistinguishable. They linked this relatively better performance of Islamic indices with the lesser diversification in such indices. Moreover, restrictions on investment by Shari'ah Board leads to investment in few sectors such as basic materials and technology. Shamsuddin (2014) concluded that both the raw returns and risk adjusted returns were higher for Shari'ah based indices relative to their conventional 
counterparts. Charles, Darne, and Pop (2015) further explained that larger firms are excluded systematically by following the SC screening criteria. As smaller stocks are riskier relative to big stocks and there is ample evidence that historically, smaller stocks relative to bigger stocks, provided better risk adjusted returns in the long run (Sadaqat \& Butt, 2017). Therefore, one reason of the SC stocks outperformed the conventional counterparts is the exclusion of bigger stocks (Charles et. al, 2015). Hoepner, Rammal and Rezec (2011) also studied the performance of Islamic Stocks. They provided evidence that the Shari'ah adherent stocks performed better due to the fact that such portfolios are mostly comprises of growth and small capitalized stocks. In addition, Hassan, Khan and Ngow (2010) identified that conventional funds tend to be more value-based and Islamic funds tend to be smaller capitalized. Similar results were also documented by (Hussein \& Omran, 2005).

The literature on the performance of SC stocks give mixed results. There are studies that document that statistically there is no difference in the performance of both group of stocks. For instance, Walkshausl and Lobe (2012) result showed no evidence that SC equities underperformed due to Shari'ah restrictions after controlling for systematic risk factors such as market, size, value and momentum. Moreover, studies such as Hussein (2004), Elfakhani, Hassan, and Sidani (2005) and Dharani and Natarajan (2011) also reported results which did not provide clear evidence on the dominance of either conventional or Islamic equities in terms of risk adjusted performance. Kraussl and Hayat (2008) also reported that, the performance of SC and NSC portfolios are not statistically significant after adjusting for systematic risk factors.

In addition to this, it is also documented previously that in comparison to NSC portfolios, SC portfolios are less volatile and therefore less sensitive to the systematic risk factors. For instance, Abdullah et al. (2007); Muhammad and Mokhtar (2008) (among others), empirically demonstrated that SC funds in Malaysia were weakly correlated with the market volatility in comparison to NSC funds. This depicts that SC stocks have less exposure to market risk and other factors. Kraussl and Hayat (2008), also provided evidence in support of lower systematic risk of SC stocks. These results show that $\mathrm{SC}$ stocks have smaller exposures toward the systematic risk factors.

Based on the above discussion, it is difficult to conclude whether SC portfolios outperform NSC portfolios or vice-versa. Therefore, in this study we empirically test the performance of SC portfolios and NSC portfolios. Pakistan equity markets is selected in this regard since in Pakistan, investors are using both types of investments. Moreover, the recent growth is SC funds also indicates an ideal setting to assess the performance of these two groups.

To accurately assess the performance of SC and NSC stocks, in this study port- 
folios are constructed using size and volatility related characteristic. The reason for selection of these two characteristics is that these are the two most important factors in emerging markets like Pakistan (Mohsin \& Butt, 2017). Moreover, to eliminate the idiosyncratic risk, the diversification theory also proposes to use portfolios instead of using individual stocks. In light of the above, following hypotheses are tested in this study:

$\mathrm{H} 1$ : SC portfolios provide better risk adjusted returns than conventional portfolios after controlling the firm size.

$\mathrm{H} 2$ : SC portfolios provide better risk adjusted returns than conventional portfolios after controlling the firm volatility.

\section{Research Methodology}

\subsection{Data and criteria for sample selection}

We extract all the stocks and accounting data through DataStream (DS) for the time period between the years 2004-2016?. We adopted the conventional cleaning procedure for the downloaded data from DS which is used by (Griffin, Kelly \& Nardari 2010; Ince \& Porter 2006). That is first we identified the extreme observations which are found in DS data and then we cleansed the data set from these observations. The screens that we apply are that we set monthly returns equal to missing if $r_{t-1}$ or $r_{t}$ and $\left(1+r_{t}\right)^{*}\left(1+r_{t-1}\right)-1<50 \%$. Furthermore, if $r_{t}$ is greater than $800 \%$ in any month, we set that months returns to missing.

After cleaning our data, we split our sample into two groups. The first group consists of the stocks which are SC. Whereas the second group consists of the stocks which are NSC. SB (consists of the screening committee of the Government of Pakistan for development of Islamic Banking and Finance in collaboration with Meezan Bank Limited), classifies a firm as SC if it fulfills the following screening criteria: (1) The core business of the company should not be prohibited by Shari'ah. (2) To avoid the interest base companies, the ratio of interest-bearing debt to total assets should be less than 37\%. (3) The NSC investments should be less than $33 \%$ of total assets. (4) The income which comes from NSC sources should be less than $5 \%$ of total income. (5) The ratio of illiquid assets to total assets should be greater than $25 \%$.

(6) The market value of the share of a company should not be less than the value of liquid asset per share.

SB provides the standard list of SC equities based on the criteria described above.

7 The data is though available from 1987 onwards but the main reason for using data from later dates is i) fewer number of stocks were listed in PSX before 2004 ii) the market was very infrequently traded and highly illiquid. 
This list was first constructed in 2008 and is updated annually. However, with the best of our efforts, we are able to get hold of this list from 2013 until 2015. In these lists, most of the firms remained identical over time. Therefore, we adopted the list of 2015 as our standard list and used the same stocks as SC stocks starting from 20048. On average, we get a sample of 85 companies which are SC and 112 companies which are NSC.

\subsection{Model}

In asset pricing literature, several asset pricing models are available to assess the performance of portfolio returns built upon different stock-based characteristics. Among these models, Capital Asset Pricing Model (CAPM) is widely used as a benchmark framework. However, due to its limited explanatory power, numerous researchers document that Fama and French (1993) model is superior at explaining portfolio expected returns. More importantly to gauge the performance of passive funds v. active funds Fama and French (2010) used the Fama and French (1993) 3-factor model. Since our study is similar in nature to Fama and French (2010) therefore, we have also implied 3-factor model in our study.

The FF model can be specified as:

$$
\mathrm{r}_{\mathrm{pt}}=\alpha_{\mathrm{p}}+\beta_{\mathrm{Mp}}\left(\mathrm{RM}_{\mathrm{t}}-\mathrm{Rf}_{\mathrm{t}}\right)+\beta_{\mathrm{SMBp}}\left(\mathrm{SMB}_{\mathrm{t}}\right)+\beta_{\mathrm{HMLp}}\left(\mathrm{HML}_{\mathrm{t}}\right)+\mu_{\mathrm{pt}}
$$

Where $r_{p t}$ shows the monthly return differential between SC and NSC firm. The is a CAPM based market risk, whereas $\mathrm{SMB}^{9}$ and $\mathrm{HML}^{10}$ are two Fama-French (1993) proposed factors. More importantly is the measure of performance between portfolios composed of SC stocks and NSC stocks. If is positive and significant then it indicates better performance of Shari'ah firms after adjusting its returns for three important risks in the market, that is market, size and value risk. These risks-based market strategies of size and value risk are constructed following guidelines prescribed in (Fama \& French,1993).

\subsection{Excess returns on shari'ah compliant stocks}

As discussed in the data section, in this study we have two main types of groups. First type of group contains the stock which are SC and the other group consists of

8 Although given the criteria of selection of Shari'ah stocks and availability of the information through Data Stream, the task of selecting the stocks is doable. However, we relied on the authentic notifications that are issued by the PSX in collaboration with Meezan Bank Limited.

9 This market-based strategy is difference between average returns of small capitalization stock portfolio ws the average returns of big capitalization stock portfolio.

10 This market-based strategy is a difference between average returns of high book-to-market stock portfolio ws the average returns of low book-to-market stock portfolio. 
such stocks which are NSC. For the SC compliant firms, we construct two volatility and size related portfolio using the median of volatility and size of all SC stocks. The stocks whose volatility or size is lesser than median of volatility ${ }^{11}$ and size ${ }^{12}$ of all SC compliant firms, are lesser volatile and smaller size SC stocks. The portfolio of such stocks in former case is indicated as LVSC firms and for later the portfolio is denoted as SSC firms. For the SC stocks whose volatility and size are higher than median is aggregated into two separate portfolios. The portfolio with volatile stocks is denoted as HVSC firms and with capitalized firm is indicated as BSC firms. This procedure of construction of portfolio is iterated for each month and the series of return is recorded for 2004-2016. Following the similar design, the four portfolios SNSC firms, BNSC firms, LVNSC firms and HVNSC firms) are constructed for NSC stocks. Table 1 Panel A exhibits the returns characteristics for volatility portfolios and Panel B exhibits returns characteristics for size portfolios. In Panel A, there are some interesting findings for instance LVSC firms have higher returns and lower standard deviation in comparison to LVNSC firms. Therefore, the Sharpe ratio is higher for LVSC firms and in essence this portfolio strictly dominates LVNSC. Similarly, HVSC firms also strictly dominates the HVNSC firms in term of average returns, standard deviation and the Sharpe ratio. Overall, these results support the second view which states that SC portfolios consists of financially stable, profitable and more stable stocks (Chowdhury \& Masih, 2015). Furthermore, to see, the overall performance of these SC and NSC stocks, we constructed four return differential (Zero-cost investment strategies) series ${ }^{13}$ which takes long position in SC portfolios and short positions in NSC portfolios, such as LVSC-LVNSC, LVSC- HVNSC, HVSC- LVNSC and HVSCHVNSC.

These average return differentials are shown in Table 1, except for the average difference of $1.01 \%$ between HVSC and LVNSC, the averages are not that high. In fact, it is negative for LVSC and HVNSC stocks. Nevertheless, the better test of performance of these returns differentials can only be gauged through the alphas of three factor model of FF (1993) model which we discuss in the coming section.

In Panel B, we see the size premium ${ }^{14}$ is present in NSC firms, for instance SNSC portfolio have on average higher returns than BNSC portfolios. For SC firms we do not see any size premium as SSC portfolio has lower returns than BSC portfolios. It is probable that Shari' ah restrictions naturally pass only those smaller firms which are

11 Volatility is defined as the standard deviation of the previous three months.

12 Size is defined as the market capitalization.

13 This difference in monthly returns of two different portfolios is commonly referred as zero-investment strategy in standard asset pricing theory but that involves using terms such as short-selling which is not allowed in Islamic finance.

14 Size premium is reported for numerous markets as smaller firms are riskier than bigger capitalization firms. 
less risky. On average, BSC portfolios produces higher returns than BNSC portfolios. To test the performance for the SC stocks versus NSC firms by controlling their size we construct four zero-cost investment strategies. These are SSC-SNSC, SSC-HNSC, BSC-SNSC, BSC-BNSC.

The main purpose of these zero-cost strategies is that we want to test, if investors get risk adjusted higher returns by investing in SC firms in comparison to NSC firms. This is of course a strong performance-based evaluation as it indicates that investment in SC firms gives anomalous returns even after adjusting for systematic risks. For that we test 3-factor model of Fama and French (1993) shown in equation (1) and the results are discussed in next section.

Table 1: Summary Statistics of Test Portfolios

\begin{tabular}{|c|c|c|c|c|c|c|}
\hline \multicolumn{7}{|c|}{ Panel A: Volatility } \\
\hline Portfolios & Mean & STD & SR & MIN & MAX & $\mathrm{N}$ \\
\hline LVNSC & $0.70 \%$ & $7.23 \%$ & $9.68 \%$ & $-31.70 \%$ & $14.80 \%$ & 141 \\
\hline HVNSC & $1.20 \%$ & $11.10 \%$ & $10.81 \%$ & $-31.30 \%$ & $37.00 \%$ & 142 \\
\hline LVSC & $0.91 \%$ & $6.69 \%$ & $13.60 \%$ & $-29.30 \%$ & $16.30 \%$ & 142 \\
\hline HVSC & $1.71 \%$ & $8.30 \%$ & $20.60 \%$ & $-19.70 \%$ & $28.70 \%$ & 142 \\
\hline LVSC-LVNSC & $0.21 \%$ & $3.19 \%$ & $6.58 \%$ & $-8.41 \%$ & $18.40 \%$ & 142 \\
\hline LVSC - HVNSC & $-0.29 \%$ & $8.27 \%$ & $-3.51 \%$ & $-31.70 \%$ & $16.90 \%$ & 142 \\
\hline HVSC - LVNSC & $1.01 \%$ & $4.80 \%$ & $21.04 \%$ & $-8.45 \%$ & $23.30 \%$ & 142 \\
\hline HVSC - HVNSC & $0.51 \%$ & $7.21 \%$ & $7.07 \%$ & $-24.50 \%$ & $33.70 \%$ & 142 \\
\hline \multicolumn{7}{|c|}{ Panel B: Size } \\
\hline Portfolios & Mean & STD & SR & MIN & MAX & $\mathrm{N}$ \\
\hline SNSC & $1.94 \%$ & $11.50 \%$ & $16.87 \%$ & $-44.60 \%$ & $44.60 \%$ & 142 \\
\hline BNSC & $0.97 \%$ & $8.03 \%$ & $12.08 \%$ & $-42.80 \%$ & $16.50 \%$ & 142 \\
\hline SSC & $1.19 \%$ & $7.77 \%$ & $15.32 \%$ & $-31.90 \%$ & $17.30 \%$ & 142 \\
\hline BSC & $1.35 \%$ & $7.74 \%$ & $17.44 \%$ & $-39.80 \%$ & $17.80 \%$ & 142 \\
\hline SSC-SNSC & $-0.75 \%$ & $7.46 \%$ & $-10.05 \%$ & $-35.80 \%$ & $22.40 \%$ & 142 \\
\hline SSC - BNSC & $0.21 \%$ & $3.84 \%$ & $5.47 \%$ & $-11.70 \%$ & $10.90 \%$ & 142 \\
\hline BSC - SNSC & $-0.58 \%$ & $8.03 \%$ & $-7.22 \%$ & $-35.90 \%$ & $19.40 \%$ & 142 \\
\hline BSC - BNSC & $0.38 \%$ & $3.52 \%$ & $10.80 \%$ & $-13.40 \%$ & $14.00 \%$ & 142 \\
\hline
\end{tabular}

This table depicts the descriptive statistics for each portfolio. Panel A shows statistics for Volatility related portfolios and Panel B shows the statistics for Size related portfolios. LVNSC is the portfolio which is constructed by using only NSC group of stocks and represents the $50 \%$ of the stock which 
have low volatility. Similarly, HVNSC are stocks which have high volatility. LVSC is the portfolio which is constructed by using only SC group of stocks and represents the $50 \%$ of the stock which have low volatility. Likewise, HVSC are the 50\% of SC stocks which have high Volatility. SNSC is the portfolio which is constructed by using only NSC group of stocks and represents the $50 \%$ of the stock which have low market Capitalization. Similarly, BNSC are stocks which have high market capitalization. SSC is the portfolio which is constructed by using only SC group of stocks and represents the $50 \%$ of the stock which have low market capitalization. Likewise, BSC are the 50\% of SC stocks which have high market capitalization. The last 4 portfolios in each panel represents the zero cost investment strategies constructed by going long in SC portfolios and shortening the NSC portfolios.

\section{Results and Analysis}

Table 2 presents the results based on FF model. Panel A reports the results of volatility related four strategies while Panel B reports the results of size related four investment strategies.

In panel A of Table 2, the risk adjusted alphas for excess returns of SC stocks over NSC stocks after controlling for volatility is shown. The results are strongly in the favor of investment in SC firms. For all four strategies such as LVSC-LVNSC, LVSC-HVNSC, HVSC-LVNSC, and HVSC-HVNSC we have positive alphas, which indicate monthly risk-free return of $0.49 \%, 1.44 \%, 0.41 \%$ and $1.60 \%$ are available. Three of these excess returns are statistically significant as well. Further these alphas are higher than their corresponding time series averages for three strategies. For instance, LVSC-LVNSC, LVSC- HVNSC, and HVSC- HVNSC have time series averages of $0.21 \%,-0.29 \%$ and $0.51 \%$. The higher alphas than corresponding time series averages is because the excess returns on the portfolios of SC stocks over NSC stocks have negative coefficient for market, size and value factors, that is, the volatility based SC firms have return patterns which are hedged against commonly referred systematic risks. The only strategy HVSC-LVNSC which has time series average of $1.01 \%$ has reduced alpha of $0.35 \%$. Understandably the high volatile SC firms are riskier than low volatile NSC stocks. As can be seen in Panel A of Table 2, this specific strategy has positive significant exposure towards and size and value-based market risks.

In panel B of Table 2, the performance of SC firms versus NSC firms after controlling for size is shown. On observation that is very important is the sign and size of alphas of the tested models. For the size-based investment strategies such as, BSC-SNSC have $1.06 \%$ and BSC-BNSC have $0.629 \%$ alphas and both are significant. Whereas, their corresponding time series averages are only $-0.58 \%$ and $0.38 \%$. Even the small sized SC firms are better hedged versus small sized NSC firms. For instance, the average return on SSC-SNSC strategy is $-0.75 \%$ but the alpha is $0.33 \%$, which is though insignificant but still higher than the time series average. The only strategy 
Table 2: Fama and French Model Results

\begin{tabular}{|c|c|c|c|c|}
\hline \multicolumn{5}{|c|}{ Panel A: Volatility Portfolios } \\
\hline Variables & LVSC-LVNSC & LVSC-HVNSC & $\begin{array}{c}\text { HVSC - LVN- } \\
\text { SC }\end{array}$ & $\begin{array}{c}\text { HVSC - HVN - } \\
\text { SC }\end{array}$ \\
\hline \multirow[t]{2}{*}{ RM } & -0.016 & -0.282 & -0.036 & -0.303 \\
\hline & $(-0.441)$ & $(-3.852)$ & $(-0.709)$ & $(-4.122)$ \\
\hline \multirow[t]{2}{*}{ SMB } & -0.174 & -0.737 & 0.329 & -0.234 \\
\hline & $(-2.384)$ & $(-4.881)$ & $(3.133)$ & $(-1.550)$ \\
\hline \multirow[t]{2}{*}{ HML } & -0.089 & -0.650 & 0.330 & -0.231 \\
\hline & $(-1.590)$ & $(-5.652)$ & $(4.115)$ & $(-1.991)$ \\
\hline \multirow[t]{2}{*}{ Constant } & 0.005 & 0.016 & 0.004 & 0.014 \\
\hline & $(1.730)$ & $(2.715)$ & $(0.854)$ & $(2.466)$ \\
\hline Observations & 142 & 142 & 142 & 142 \\
\hline R-squared & 0.056 & 0.40 & 0.138 & 0.205 \\
\hline \multicolumn{5}{|c|}{ Panel B: Size Portfolios } \\
\hline Variables & SSC-SNSC & SSC-BNSC & BSC - SNSC & BSC - BNSC \\
\hline \multirow[t]{2}{*}{ MR } & -0.329 & -0.078 & -0.310 & -0.059 \\
\hline & $(-4.410)$ & $(-1.900)$ & $(-4.288)$ & $(-1.540)$ \\
\hline \multirow[t]{2}{*}{$\mathrm{SMB}$} & -0.385 & -0.376 & -0.990 & -0.229 \\
\hline & $(-2.500)$ & $(-4.471)$ & $(-6.644)$ & $(-2.884)$ \\
\hline \multirow[t]{2}{*}{ HML } & -0.233 & 0.093 & -0.320 & 0.006 \\
\hline & $(-1.975)$ & (1.439) & $(-2.807)$ & $(0.100)$ \\
\hline \multirow[t]{2}{*}{ Constant } & 0.003 & -0.001 & 0.011 & 0.006 \\
\hline & $(0.560)$ & $(-0.296)$ & $(1.860)$ & $(2.056)$ \\
\hline Observations & 142 & 142 & 142 & 142 \\
\hline R-squared & 0.235 & 0.135 & 0.38 & 0.084 \\
\hline
\end{tabular}

This table presents the results of Fama and French (1992) model.

$r_{p t}=\alpha_{p}+\beta_{\text {RM }}\left(R_{t}-R f_{t}\right)+\beta_{\text {SMBp }}\left(\mathrm{SMB}_{\mathrm{t}}\right)+\beta_{\text {HMLP }}\left(\mathrm{HML}_{\mathrm{t}}\right)+\mu \mathrm{p}_{\mathrm{t}}$

In Pane $\mathrm{A}$, the results of test portfolios constructed by using volatility related information are presented. In Panel B, the results of size related portfolios are depicted. The time period for this analysis is from May 2004 to February 2016. In the last row, R2 values are reported in both the panels. T-stats are given in parenthesis.

LVSC = Low Volatility SC Portfolio, HVSC = High Volatility SC Portfolio, LVNSC = Low Volatility Non-NSC portfolio, HVNSC $=$ High Volatility NSC portfolio, SSC $=$ Small Size SC Portfolio, BSC = Big Size SC Portfolio, SNSC = Small Size NSC portfolio, BNSC = Big Size NSC portfolio. 
which is positively exposed to market-based risk is SSC-BHSC, this is understandable that small sized SC firms are riskier than big NSC firms. The results of sized based portfolios are consistent with the studies of (Charles et al., 2015; Hoepner et al., 2011; Hassan et al., 2010). Our general finding is that the SC bigger sized firms and lesser volatile SC firms have far superior performance in comparison to their counterpart NSC firms.

\section{Conclusions}

It is theoretically arguable that Shari'ah constraints, SC portfolios underperform compared to NSC portfolios. The diversification opportunities are limited in SC stocks as the universe of stocks decreases due to Shari'ah restrictions. On the other hand, taking lesser exposure towards market risk by investing in less risky firms also have some theoretical advantages. In this paper, we empirically explore the performance of SC portfolios versus NSC portfolio after controlling for volatility and size for the stocks traded in PSX for the time period between the years 2004-2016. Our performance evaluation criteria are the alphas of Fama and French (1993) for the time series of return differentials of portfolios composed of SC and NSC firms.

This study tests eight investment strategies which goes long in SC stocks and short in NSC stocks. Theoretically the alphas of 3-factor model for such strategies should be indistinguishable from zero. If alphas are positive/negative, then results indicate that investment in SC/NSC is superior. We find that out of eight strategies, the alphas are positive for seven times and they are significant for five times. Especially the least volatile and big sized SC compliant stocks perform better than both least/higher volatile and small/big sized NSC firms. Further their performance is also better than higher volatile and small sized SC firms.

In a nutshell we can say that the SC firms fulfils the hedging requirements of the investors and their returns do not drop that much when overall returns in markets are lower or the investors in NSC firms are doing worse. However, this study does not allude that overall returns on NSC stocks can be higher than SC firms. But evidence suggests that risk adjusted returns are better for SC stocks. Lastly, we do not find any substantial evidence for opportunity loss due to limited diversification opportunities, instead returns on SC firms are negatively linked with market-based risk factors and that indicate higher demand of such assets by investors. This part of narration is supported strongly by least volatile and big sized SC firms. This study has important implications for asset managers investors. Asset managers should consider $\mathrm{SC}$ stocks in their portfolios in order to benefit from the superior performance of SC portfolios over the NSC portfolios. For investors who wish to trade actively may also consider SC portfolios. Moreover, the results of this study have directions for 
future research as well. Since SC portfolios are less exposed to systematic risk factors therefore it would be interesting to assess the performance of SC portfolios in different market conditions or business cycles. Lastly, other systematic factors such as liquidity, profitability and investment should also be considered to assess the exposures of SC portfolios towards these systematic risk factors.

\section{References}

Abdullah, F., Hassan, T., \& Mohamad, S. (2007). Investigation of performance of Malaysian Islamic unit trust funds: Comparison with conventional unit trust funds. Managerial Finance, 33(2), 142-153.

Aka, J. (2009). Shari'ah investing: Through bull and bear markets? SEI investments (Middle East), October 2009. (Retrieved Nov 15, 2017 at) www.seic.com/enME/about/MiddleEast/SEI-Shari'ahh-BullAndBearMarkets.pdf

Al-Khazali, O., Lean, H. H., \& Samet, A. (2014). Do Islamic stock indexes outperform conventional stock indexes? A stochastic dominance approach. Pacific-Basin Finance Journal, 28, 29-46.

Al-Shakfa, O., \& Lypny, G. (2011) Islamic investment and the cost of observance. The Journal of Investing, 20(2), 101-09.

Alam, N., \& Rajjaque, M. S. (2010). Shari'ah-compliant equities: Empirical evaluation of performance in the European market during credit crunch. Journal of Financial Services Marketing, 15(3), 228-40.

Alhenawi, Y., Hassan, M. K., \& Merdad, H. (2010). Islamic versus conventional mutual funds' performance in Saudi Arabia: a case study. Journal of King Abdulaziz University: Islamic Economics, 23(2), $163-200$.

Ashraf, D., Felixson, K., Khawaja, M., \& Hussain, S. M. (2017). Do constraints on financial and operating leverage affect the performance of Islamic equity portfolios? Pacific-Basin Finance Journal, 42, 171-182.

Ashraf, D., \& Mohammad, N. (2014). Matching perception with the reality - Performance of Islamic equity investments. Pacific-Basin Finance Journal, 28, 175-89.

Banz, R. W. (1981). The relationship between return and market value of common stocks. Journal of Financial Economics, 9(1), 3-18.

Basu, S. (1977). Investment performance of common stocks in relation to their pricelearnings ratios: A test of the efficient market hypothesis. The Journal of Finance, 32(3), 663-682.

Bello, Z. Y. (2005). Socially responsible investing and portfolio diversification. Journal of Financial Research, 28(1), 41-57.

Bousalam, I., \& Hamzaoui, M. (2016). Impact of ethical screening on risk and return: The case of constructed Moroccan Islamic stock indexes. MPRA Working Paper. Available at:

https://mpra.ub.uni-muenchen.de/68979/. 
Charles, A., Darne, O., \& Pop, A. (2015). Risk and ethical investment: Empirical evidence from

Dow Jones Islamic indexes. Research in International Business and Finance, 35, 33-56.

Chowdhury, M. A. F., \& Masih, M. (2015). Socially responsible investment and Shariah-compliant investment compared: Can investors benefit from diversification? An ARDL approach. MPRA Paper. Available at: https://mpra.ub.uni-muenchen.de/65828/1/MPRA_paper_65828.pdf

Dharani, M., \& P. Natarajan. 2011. Equanimity of risk and return relationship between Shari'ahh index and general index in India. Journal of Economics and Behavioral Studies, 2, 213-22.

Elfakhani, S., Hassan, M. K., \& Sidani, Y. (2005). Comparative performance of Islamic versus secular mutual funds. $12^{\text {th }}$ Economic Research Forum Conference, University of New Orleans, New Orleans, LA, November 2005.

Fama, E. F., \& French, K. R. (1992). The crosslsection of expected stock returns. The Journal of Finance, 47(2), 427-465.

Fama, E. F., \& French, K. R. (1993). Common risk factors in the returns on stocks and bonds. Journal of Financial Economics, 33(1), 3-56.

Fama, E. F., \& French, K. R. (2010). Luck versus skill in the cross\section of mutual fund returns. The Journal of Finance, 65(5), 1915-1947.

Fama, E. F., \& French, K. R. (2014). A five-factor asset pricing model. Journal of Financial Economics, $116(1), 1-22$.

Griffin, J. M., Kelly, P. J., \& Nardari, F. (2010). Do market efficiency measures yield correct inferences? A comparison of developed and emerging markets. The Review of Financial Studies, 23(8), 3225-3277.

Hayat, R., and R. Kraeussl. (2011). Risk and return characteristics of Islamic equity funds. Emerging Markets Review, 12, 189-203.

Ho, C. S. F., Rahman, N. A. A., Yusuf, N. H. M., \& Zamzamin, Z. (2014). Performance of global Islamic versus conventional share indices: International evidence. Pacific-Basin Finance Journal, 28, 110-121.

Hoepner, A. G., Rammal, H. G., \& Rezec, M. (2011). Islamic mutual funds' financial performance and international investment style: Evidence from 20 countries. The European Journal of Finance, 17(9-10), 829-850.

Hou, K., Xue, C., \& Zhang, L. (2015). Digesting anomalies: An investment approach. The Review of Financial Studies, 28(3), 650-705.

Hou, K., Xue, C., \& Zhang, L. (2017). Replicating Anomalies. Working Paper No. w23394, National Bureau of Economic Research.

Hussein, A. K. (2004). Ethical investment: Empirical evidence from FTSE Islamic index. Islamic Economic Studies. 12, 21-40. 
Hussein, K., \& Omran, M. (2005). Ethical investment revisited: evidence from Dow Jones Islamic indexes. The Journal of Investing, 14(3), 105-126.

Ince, O. S., \& Porter, R. B. (2006). Individual equity return data from Thomson DataStream: Handle with care! Journal of Financial Research, 29(4), 463-479.

Jaffe, J., Keim, D. B., \& Westerfield, R. (1989). Earnings yields, market values, and stock returns. The Journal of Finance, 44(1), 135-148.

Kabir Hassan, M., Nahian Faisal Khan, A., \& Ngow, T. (2010). Is faith-based investing rewarding? The case for Malaysian Islamic unit trust funds. Journal of Islamic Accounting and Business Research, 1(2), 148-171.

Kraussl, R., \& Hayat, R. (2008). Risk and return characteristics of Islamic equity funds. Social Science Research Network (SSRN) Paper. Available at: http://ssrn.com/abstract1/41320712.

Lintner, J. (1965). Security prices, risk, and maximal gains from diversification. The Journal of Finance, 20(4), 587-615.

Masih, M., Kamil, N. K., \& Bacha, O. I. (2018). Issues in Islamic equities: A literature survey. Emerging Markets Finance and Trade, 54(1), 1-26.

Markowitz, H. (1952). Portfolio selection. The Journal of Finance, 7(1), 77-91.

Muhammad, N., \& Mokhtar, M. (2008). Islamic equity mutual fund performance in Malaysia: Risk and return analysis. Proceedings of the Malaysian Finance Association (MFA) Conference, 2008.

Sadaqat, M., \& Butt, H. A. (2017). Role of Liquidity in Explaining Anomalous Returns: Evidence from Emerging Market. Business $\mathcal{E}$ Economic Review, 9(3), 1-35.

Peillex, J., \& Ureche-Rangau, L. (2013). Is there a place for a Shari'ahh-Compliant index on the Paris stock market? International Journal of Business, 18(2), 131-50.

Rosenberg, B., Reid, K., \& Lanstein, R. (1985). Persuasive evidence of market inefficiency. The Journal of Portfolio Management, 11(3), 9-16.

Sharpe, W. F. (1964). Capital asset prices: A theory of market equilibrium under conditions of risk. The Journal of Finance, 19(3), 425-442.

Shamsuddin, A. (2014). Are Dow Jones Islamic equity indices exposed to interest rate risk? Economic Modelling, 39, 273-81.

Sukmana, R., \& Kolid, M. (2012). Impact of global financial crisis on Islamic and conventional stocks in emerging market: An application of ARCH and GARCH method. Asian Academy of Management Journal of Accounting E Finance, 31(2), 357-370.

Walkshausl, C., \& Lobe, S. (2012). Islamic investing. Review of Financial Economics, 21, 53-62. 